\title{
Long-wave radiation balances of the south-west Poland
}

\author{
Krystyna Bryśs ${ }^{1, *}$, Tadeusz Bryś ${ }^{2}$, and Arkadiusz Głogowski ${ }^{1}$ \\ ${ }^{1}$ Wroclaw University of Environmental and Life Science, Faculty of Environmental Engineering \\ and Geodesy, pl. Grunwaldzki 24, 50-363 Wrocław, Poland \\ ${ }^{2}$ Polish Geophysical Society, Wrocław Division, pl. Grunwaldzki 24, 50-363 Wrocław, Poland
}

\begin{abstract}
The paper goal is to show trends of seasonal and year to year variability of long-wave radiation balances of the active surface in SW Poland, taking into account the standard meteorological data from 1971-2000 for Jelenia Góra, Kłodzko, Legnica, Leszno, Opole, Wrocław and Mt. Śnieżka. The average monthly values of these balances were calculated using the selected two variants of the Brunt's formula (standard and modified by Michałowska-Smak). In the researched 30-year courses prevail positive trends but with different statistical significance. The analysed trends of the average annual values have been compared with appropriate trends of air temperature, sunshine duration and cloudiness to understand the regional relations of the long-wave radiation balance to these parameters of the climatic variability. These analyses are essential part of wider research fields on long-term variability and trends of net radiation fluxes and their components on different active surfaces in Lower Silesia.
\end{abstract}

\section{Introduction}

The Earth's net long-wave radiation is not related to an effective temperature but is related to a actual temperature of this planet's surface. The Earth's effective temperature is the temperature of a black body that would emit the same total amount of electromagnetic radiation. Therefore, the such calculated planet's temperature differs from an actual temperature of this planet's surface, because assumes that the body is a black body on the base of an emitted heat radiation, according to the Stefan-Boltzmann law. The law states that the total energy radiated per unit surface area of a black body across all wavelengths per unit time $\mathrm{F}_{\mathrm{Bol}}$ is directly proportional to the fourth power of the black body's effective temperature $T$ eff: $\mathrm{F}$ Bol $=\sigma \cdot T_{\text {eff }}{ }^{4}$ (where: $\sigma$ is the value of the Stefan-Boltzmann constant) [1]. The other form of this formula: $E_{c}=\varepsilon \cdot \sigma^{\cdot} T^{4}$ takes into account of the emissivity coefficient $\varepsilon$ (mainly for so-called grey bodies) into account [2]. When the planet's net emissivity in the relevant wavelength band is less than unity, that is less than that of a black body, the actual temperature of the body, as it is in the Earth's case, will be higher than the effective temperature. The net emissivity may be low due to surface or atmospheric properties, including greenhouse effect $[2,3]$.

* Corresponding author: krystyna.brys@up.wroc.pl 
The strong increase in the surface temperature of the Earth and other adverse climatic changes observed in recent decades [3] are closely related to changes in the Earth's radiation balance. Measurements and studies of the long-wave radiation balance of various active surfaces of the Earth, in various spatial and temporal scales, are therefore an important scientific challenge, which is closely related to the forecasting of climate threats to humans and life on Earth. This work aims to present trends changes in the long-term radiation balance in the regional aspect, bearing in mind the south-western part of Poland.

\section{Materials and methods}

The net long-wave radiation $L^{*}$ of any active surface of the Earth is the difference between the radiation of the atmosphere $L \downarrow$ and the radiation of the analyzed active surface of the Earth $L \uparrow[1]$.

$$
L^{*}=L \downarrow-L \uparrow
$$

The $L^{*}$ equation is an important part of the solar irradiation balance (net radiation) $R_{n}$, which is the sum of two partly balances: the short-wave radiation balance (net short-wave radiation) $K^{*}$ and the long-wave radiation balance (net long-wave radiation) $L^{*}[1,2]$ :

$$
R_{n}=K^{*}+L^{*}
$$

A revenue in the balance $K^{*}$ sheet is the short-wave solar irradiation (also called: global or total radiation) $K \downarrow$ and an expenditure in the balance $K^{*}$ sheet is the reflected short-wave solar irradiance $K \uparrow$, so the formula $K^{*}$ has a form [2]:

$$
K^{*}=K \downarrow-K \uparrow
$$

The $L^{*}$ formulas used in this paper are modifications of the original Brunt's formula [1], in which no distinction is made between these two streams, but the method of calculating the total value of these streams is given:

$$
R_{e f}=\sigma \cdot T^{4} \cdot\left(a-b \cdot e^{0,5}\right) \cdot(1-c \cdot C)
$$

where:

$R_{e f}$ - is the net long-wave radiation in cal $\cdot \mathrm{cm}^{-2}$ per day,

$a, b$-coefficients depending on the water vapour content of the air

$c$ - coefficient depending on the type of cloudiness

$e-$ is the water vapour partial pressure in millibars (measured at the level of $2 \mathrm{~m}$ ),

$T$ - is the air scren temperature in degres Kelvin (measured at the level of $2 \mathrm{~m}$ ),

$C-$ is the cloud cover in tenths,

$\sigma-$ is the Stefan-Boltzmann constant $\left(1.35 \cdot 10^{-4} \mathrm{cal} \cdot \mathrm{cm}^{-2} \cdot \mathrm{K}^{-4}\right)$.

Two modifications of this formula were applied in the paper. The first one, called here: "Brunt's equation (sunshine duration") is based on Penman's modification [4] and in the version of Kędziora [2] for climatic conditions of Poland has a form:

where:

$$
L^{*}=\sigma \cdot T^{4} \cdot\left(0.56-0.08 \cdot e^{0,5}\right) \cdot(0.1+0.9 \cdot u)
$$

$L^{*}$ - is the net long-wave radiation in $\mathrm{W} \cdot \mathrm{cm}^{-2}$ per day

$\sigma-$ is the Stefan-Boltzmann constant $\left(5,6710^{-8} \mathrm{~W} \cdot \mathrm{m}^{-2} \cdot \mathrm{K}^{-4}\right)$. 
$u-$ is the relative sunshine duration (from 0 to 1 ).

The second modification, which is based on the Michałowska-Smak pattern [5] and is called here: "Brunt's equation (cloudiness)" has a form:

$$
L^{*}=\sigma \cdot T^{4} \cdot\left(0.36-0.041 \cdot e^{0,5}\right) \cdot\left(1-0.75 \cdot \mathrm{n}^{1,4}\right)
$$

where the value of $L^{*}$ is in in $\mathrm{cal} \cdot \mathrm{cm}^{-2}$ per day and $\sigma$ is in $\mathrm{cal} \cdot \mathrm{cm}^{-2} \cdot \mathrm{K}^{-4}$.

Using these two modifications, the average monthly values $\left(\mathrm{W} / \mathrm{m}^{2}\right)$ of the balance of long-wave $L^{*}$ radiation for selected meteorological stations of the south-west Poland in the years 1971-2000 were calculated. The basis of calculations were average monthly values of air temperature $(\mathrm{K})$, water vapor pressure $(\mathrm{hPa})$, cloud cover (on a scale of $0-8$ ) and relative sunshine duration (0-1) for seven synoptic stations in the south-western Poland (city stations: Jelenia Góra, Kłodzko, Legnica, Leszno, Opole, Wrocław and the mountain station: Śnieżka). These data for the tested 360 months were obtained from the IMGW online database [6]. Urban stations are characterized by a standard grassy active surface, while the active area of Śnieżka (1602 m a.s.l.) is mixed grassy-stony (grass and rock rubble), typical for the highest, high-altitude climatic-vegetation floor of the Giant Mountains. In winter and early spring, these surfaces, in varying degrees and on different days for particular years, are often covered with snow (the longest, on average from November to April, snow cover occurs on Śnieżka).

Seasonal, semi-annual and annual variability of $L^{*}$ values were analyzed and linear $L^{*}$ trends were compared for the surveyed stations in the period 1971-2000.

\section{Results and discussion}

The average annual $L^{*}$ for the analysed 30 years was tested in all tested stations (Fig. 1). Results shows a clear seasonal variation in which, apart from the solar-radiative determinant [1, 2], circulation factors have a significant contribution [3, 4]. The impact of the latter factors is reflected in the summer half-year in June-July weakening of the $L^{*}$ value, compared to May and August. This is visible in the $L^{*}$ values calculated on the grounds of both the Brunt formulas used in the work. In May there is an annual culmination, with the highest values of around $60 \mathrm{~W} / \mathrm{m}^{2}$ for Leszno, Wrocław and Legnica using the formula with sunshine duration. For the $L^{*}$ values calculated from the second formula, the August culmination appears most often, with the highest values of about $55 \mathrm{~W} / \mathrm{m}^{2}$. 

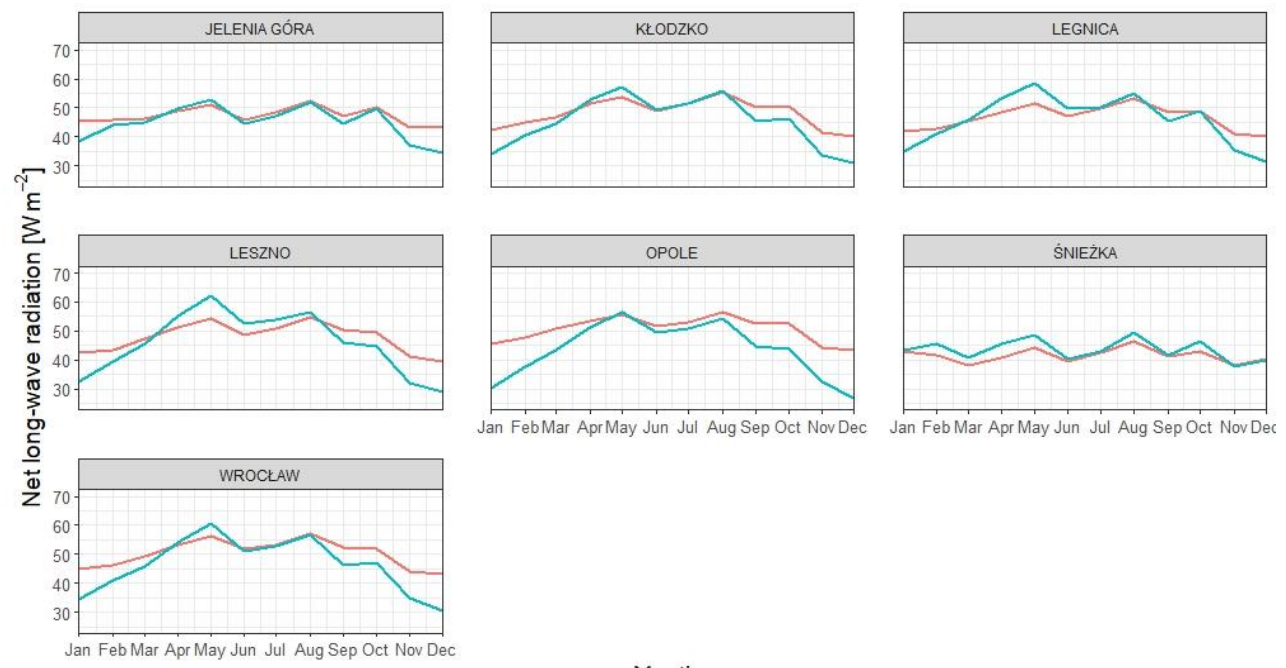

Months

Methods - Brunt equation (sunshine duration) - Brunt equation (cloudiness)

Fig. 1. Annual average values of $\mathrm{L}^{*}$ for the studied 7 stations in south-west Poland, calculated by means of two selected modifications of Brunt's formula: Brunt's equation (sunshine duration) and Brunt's equation (cloudiness).

Only for Śnieżka there are clearly lower $L^{*}$ values, and the annual culmination in August for the average monthly values $L^{*}$ calculated by the formula "Brunt's equation (cloudiness)" approaches $45 \mathrm{~W} / \mathrm{m}^{2}$. Apart from Śnieżka, where for almost a whole year the values calculated from the formula "Brunt's equation (sunshine duration)" prevail, in the cold half-year, and especially in November-February months, the majority of stations has a clear dominance of the values calculated by the second formula. This time coincides with the period of the highest cloudiness in the year, especially the more frequent presence of low and middle floor clouds and the highest frequency of fogs, especially in the Sudetes. It is important also, due to a bigger albedo, the relatively long period with snow cover for Śnieżka. The snow cover affects the increase of reflected short-wave solar radiation $K \uparrow$. This all has a negative effect on the inflow of the total radiation $K \downarrow$ and decreases of the net short-wave radiation $K^{*}$ fluxes and affects the relative increase in the importance of $L \downarrow$ in $L^{*}$ and in the entire radiation balance $R_{n}$ [7]. However, only a comparison of the calculated values of $L^{*}$ with the measured values will allow to analyze and assess the reliability of the results obtained, and thus usefulness for the climatic conditions of the south-western part of Poland of the both Brunt's formulas used in the work.

The courses of the mean monthly values of the net long-wave radiation $L^{*}$ fluxes, which were calculated from the selected modifications of the Brunt's formulae (Brunt's equation (sunshine duration) and Brunt's equation (cloudiness)), in the years 1971-2000 are shown in Fig. 2 on example of Opole (upper graphs) and Wrocław (lower graphs). 


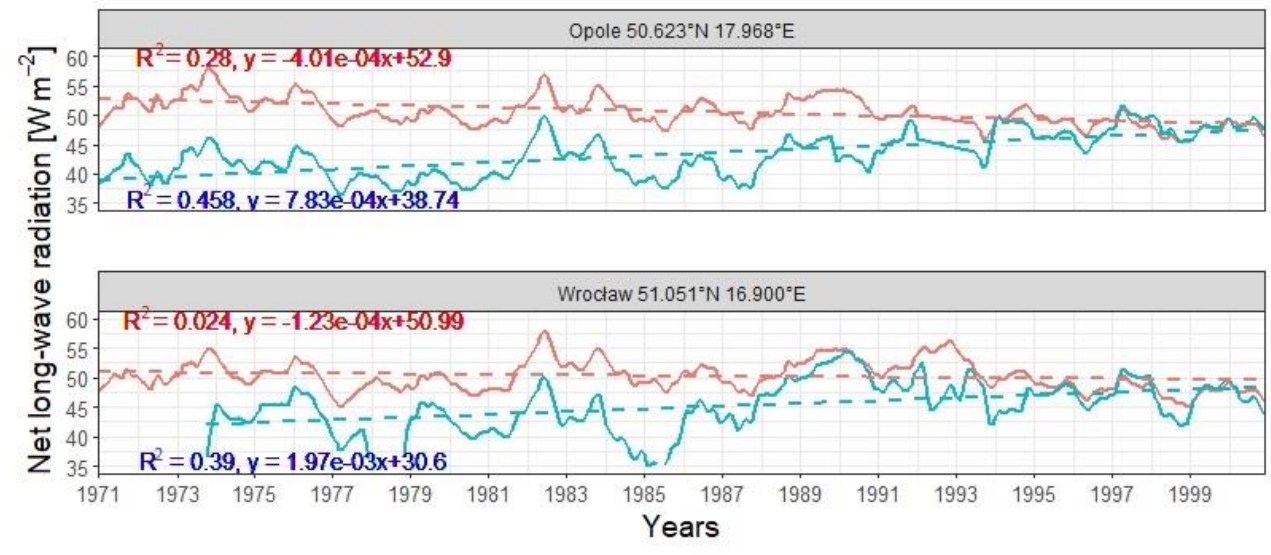

Methods - Brunt equation (sunshine duration) - Brunt equation (cloudiness)

Fig. 2. The courses in the years 1971-2000 of the mean monthly values of the net long-wave radiation $L^{*}$ fluxes, which were calculated by using of the Brunt's equation (sunshine duration) and the Brunt's equation (cloudiness)), in Opole (upper graphs) and Wrocław (lower graphs).

The opposite of the trends calculated from these two formulas draws attention here, because the trends of the formula taking into account sunshine duration are positive, while for the second formula they are negative. These trends, apart from the $L^{*}$ values calculated from the second formula (cloudiness) for Wrocław, are statistically significant at the 0.01 level (2-tailed). This opposition is further accentuated by graphs of linear trends for 12-month moving average values for the 30-year surveyed presented in Fig. 3 for all seven analyzed stations. The strongest growth trends $L^{*}$ are calculated from the formula that takes sunshine duration on board for Opole, Wrocław and Legnica, however for the latter two are partly related to slightly shorter time series and influence on the directional coefficient of the $L^{*}$ reduction trend in the second half of the 70s (Fig. 2). The weakest upward trend, which is statistically insignificant, applies to Śnieżka (Fig. 3 on the left). Other $L^{*}$ growth trends are statistically significant. On the other hand, declining linear trends for the $L^{*}$ values calculated from the "Brunt's equation (cloudiness)" formula are usually statistically insignificant, with the exception of Opole and Legnica (Fig. 3 on the right).
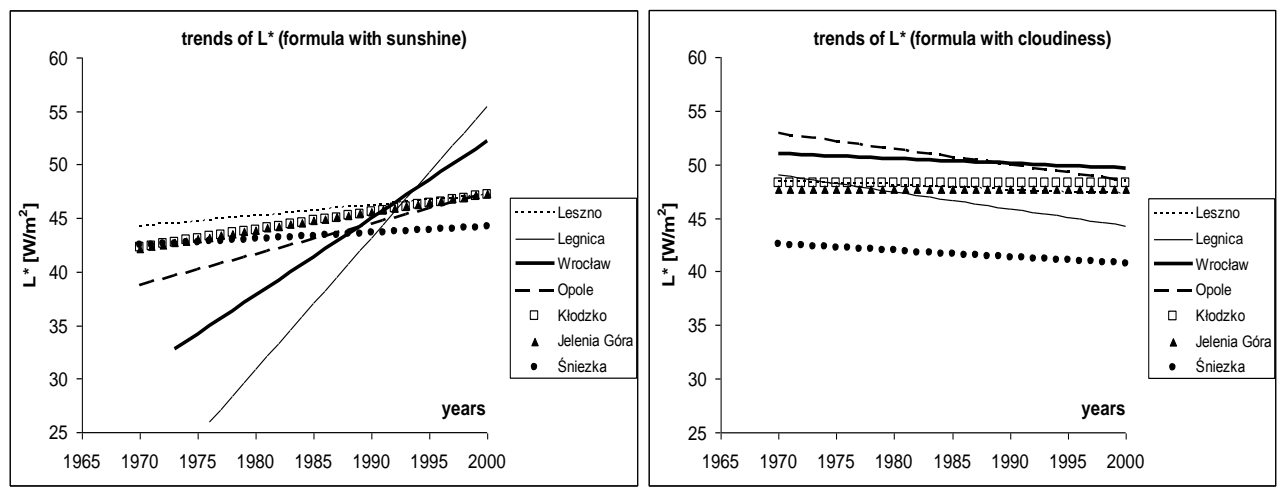

Fig. 3. The courses in the years 1971-2000 of the linear trends of the 12-month mean running values of the net long-wave radiation $L^{*}$ fluxes, which were calculated by using of the Brunt's equation (sunshine duration) (on the left) and the Brunt's equation (cloudiness) (on the right), for the selected 7 stations in the south-west Poland. 
The comparison of monthly, seasonal and annual $L^{*}$ values obtained for Wrocław with $L^{*}$ measured values in 2007-2017 (Fig. 4) shows their a better mutual matching for the values calculated with the "Brunt equation (cloudiness)" formula than those calculated with the "Brunt equation (sunshine duration)" formula. Nevertheless, there are relatively large deviations of $L^{*}$ values calculated from the measured values, and especially the bigger deviations in the monthly values in the following years, which suggest the need to further improve the modification of the Brunt formula in its regional applications. They must be their coefficients better adjusted to specific regional climatic conditions and probably instead of sunshine duration or cloudiness the value $K \downarrow$ should be introduced into $L^{*}$ calculations [7].
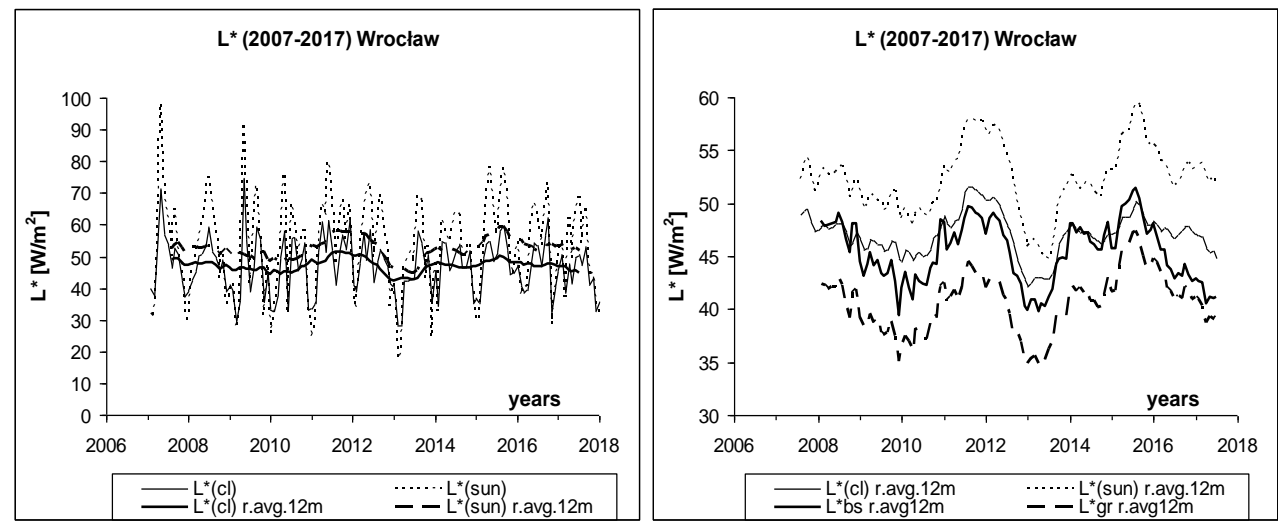

Fig. 4. The courses of monthly and twelve month running average values (r.avg.12 m) of the long-wave radiation balance calculated on the base of Brunt's equation (cloudiness) $L *(c l)$ and Brunt's equation (sunshine duration) $L^{*}($ sun $)$ (on the left) and a comparison of these 12-month running average values with the appropriate measured values of $\mathrm{L}^{*}$ for bare soil $L^{*} b s$ and grassy area $L^{*} \operatorname{gr}$ (on the right) in the years 2007-2017 in Wrocław.

This conclusion was confirmed also by a comparison of the analysed long-wave radiation trends with appropriate positive trends of air temperature (Tair), sunshine duration $(S)$ and cloudiness $(C)$, because their variability is different in following seasons for the researched stations. It is related, mainly to cloudiness, because its a seasonal variability is connected with different types of clouds and variability their physical features. This fact only partially explains, why positive trends both for 12-month average running values of cloudiness and sunshine are observed (Fig. 5). The values of relative $S$ (i.e. as a percentage share of daily value of $S$ in relation to a length of day) and C (as a percentage share clouds in sky covering), after all, should be a mutual complement to $100 \%$ of share in the following days and months. Of course, it is related only to daily hours, and clouds may appear also during the night and such situation can affect the observed trends of cloudiness and $L^{*}$, especially in cold half-year, when are longer nights. These examples show, as complicated are relations between cloudiness and sunshine duration. Their proper clarification demands often detailed analyses and longer research works.

On the other hand, in these stations has occurred an absence of a statistical significant both positive and negative statistical significant trends for vapour pressure $(e)$. The variability of the mean monthly $T p, S, C, e$ values and their trends are performed only on Wrocław example (Fig. 5), but the directions of the trends in other meteorological stations of the south-western part of Poland are similar, but with different inclination,. Therefore, the long-term variations these parameters with different force influence on a forming of the mentioned above coefficients of the Brunt's formula in the regional scale. The additional 
detailed analysis are need in the future to better understand the regional relations of the long-wave radiation balance to these parameters of the climatic variability.
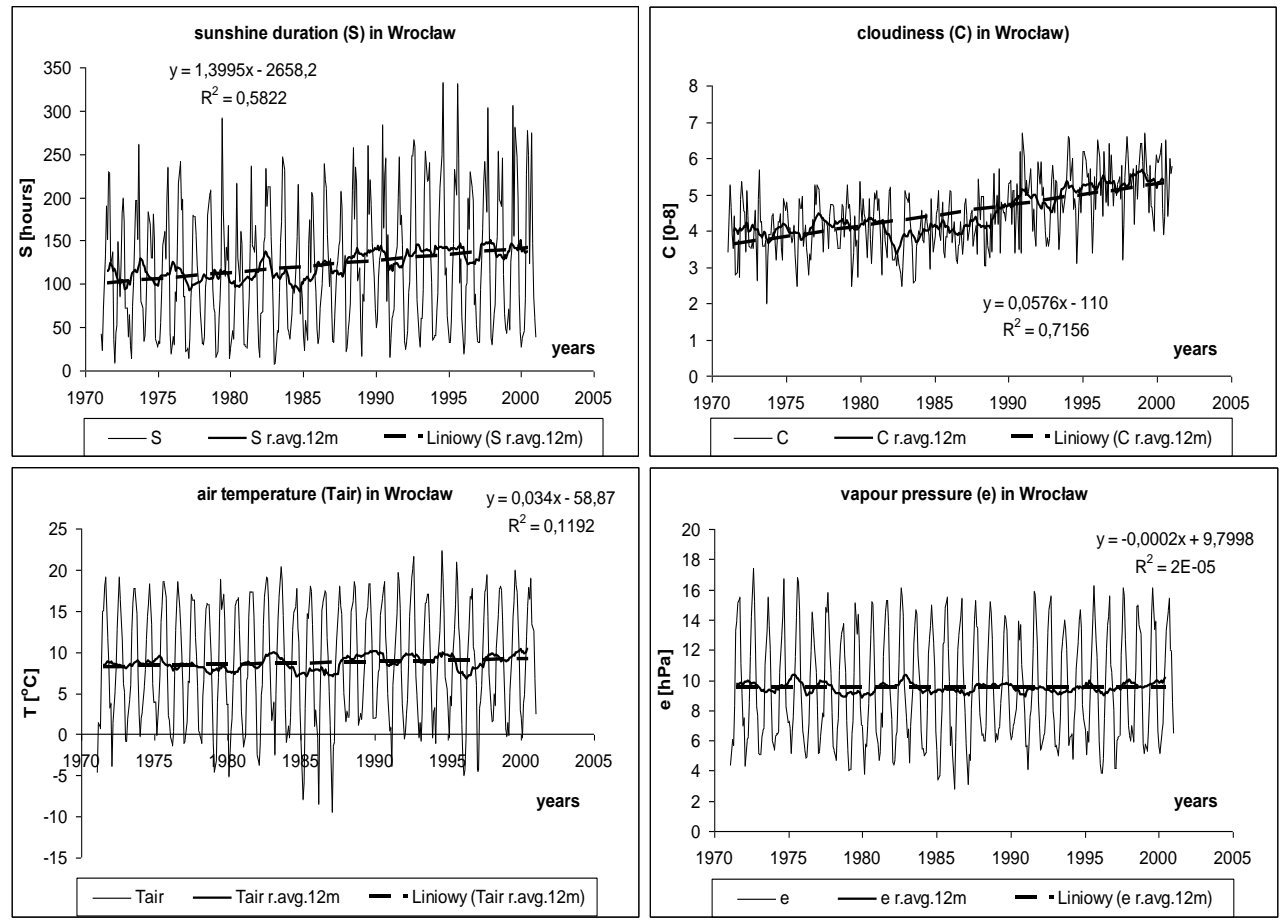

Fig. 5. The courses of monthly and twelve month running average values (r.avg.12 m) of the sunshine duration (S), cloudiness (C), air temperature (Tair), vapour pressure (e) in the years 1971-2000 in Wrocław. (Explanation: Linear $=$ Linear trend, the all data are from station Wrocław-Strachowice, but monthly S values for the years 1971-1972 are interpolated from station Wrocław-Swojec).

\section{Conclusions}

Averaged over the 30 years of the study, the annual values of net long-term radiation balance $L^{*}$ in all the studied stations shows a clear seasonal variation, with a May or August peak and a winter minimum. The results for south-western Poland, obtained with the use of two different modifications of the Brunt $L^{*}$ formula, most often show two opposite trends for the years 1971-2000. Annual mean values of $L^{*}$ calculated from the formula taking into account relative sunshine duration, on the example of six analysed city stations and one mountain station, generally show a significant upward trend. Appropriate linear trends for $L^{*}$ values calculated from the Michałowska-Smak formula, which does not take into account sunshine duration, but coefficients for cloudiness, show a statistically insignificant downward trend. The comparison of monthly, seasonal and annual $L^{*}$ values obtained for Wrocław with $L^{*}$ measured values in 2007-2017 shows their a better mutual matching for the values calculated with the "Brunt equation (cloudiness)" formula than those calculated with the "Brunt equation (sunshine duration)" formula. This comparison, as well as the studies of $L^{*}$ variability in south-western Poland, conducted for a representative in climatology of the $30^{\text {th }}$ decade, 1971-2000, indirectly prove that the precise capture of this variability requires the use of new modifications of Brunt's formula. These modifications should be based on regional coefficients $a, b, c$ to Brunt's formula 
(derived for specific, regional climatic conditions) and the use of total radiation $K \downarrow$ instead of relative sunshine duration or cloudiness. Striving for a more accurate capture of $L^{*}$ values is important, both in the regional and wider context, because of the bioclimatic application of these results [9-10], their role in areal evaporation [2, 4, 7] and their importance in studies of the effects of radiation changes on climate change [3,8].

This final conclusion was confirmed also by a comparison of the analysed long-wave radiation trends with appropriate trends of air temperature, sunshine duration and cloudiness to understand the regional relations of the long-wave radiation balance to these parameters of the climatic variability. These analyses are essential part of wider research fields on long-term variability and trends of the net radiation fluxes and their components on different active surfaces in Lower Silesia [7, 8]

\section{References}

1. D. Brunt, Physical and Dynamical Meteorology (Cambridge University Press, 1939)

2. A. Kędziora, Fundamentals of agro-meteorology (PWRiL, Poznań, 2008)

3. T. F. Stocker, Climate change 2013 (IPCC, 2013)

4. H. L. Penman, Proceedings of the Royal Society A. 1032, 193 (1948)

5. A. Michałowska-Smak, Publ. Inst. Geophys. Pol. Acad. Sc. 132, D-9 (1979)

6. https://dane.imgw.pl/ (accessed on 06/05/2019)

7. K. Bryś, Dynamics of net radiation balance of grass surface and bare soil (University of Environmental and Life Science Publish. Monographs CLXII, Wrocław, 2013)

8. K. Bryś, T. Bryś, H. Ojrzyńska, Long-wave radiation balances of grassy surface and bare soil in Wroctaw (Proccedings ASEE 2019)

9. K. Błażejczyk, P. Broede, D. Fiala, G. Havenith, I. Holmer, G. Jendritzky, B. Kampmann, Przeglad Geograficzny 82, 1 (2010)

10. K. Bryś, H. Ojrzyńska, Acta Geographica Lodziensia, 104 (2016) 